\title{
Ventricular Obstruction Due to Ectasia of The Internal Carotid Artery
}

\author{
A. R. HUDSON and C. G. GONSALVES
}

SUMMARY: This is a report of the first recorded instance of ventricular obstruction at the foramen of Monro by an ectatic carotid artery. The clinical course, investigations and treatment are described.

RÉSUMÉ: Ce rapport concerne le premier exemple publié d'obstruction ventriculaire résultant d'une obstruction du foramen de Monro par une artère carotide ectopique. L'évaluation cliniques, les investigations et le traitement son décrits.

From the departments of Neurosurgery \& Radiology, St. Michael's Hospital, University of Toronto.

Reprint requests to Dr. Alan R. Hudson, Assistant Professor, Dept. of Neurosurgery, 30 Bond Street, Toronto, Ontario M5B IW8.
There are no reports in the literature of ventricular obstruction due to ectasia of the internal carotid artery. This case report records the occurrence.

\section{CASE REPORT}

A 56-year-old right-handed male presented with a history of progressive dementia, disturbance of gait, and urinary incontinence over a three-month period. He had become more drowsy and was seen in the emergency department unconscious. Examination revealed some response to pain and a mild left hemiparesis. The fundi showed no abnormality. He had bilateral Babinski responses.

Skull $\mathrm{X}$-rays revealed tubular calcification high above the sella turcica in the mid-line (Fig. 2). Left carotid angiography demonstrated marked elongation and moderate irregular dilatation of the supraclinoid segment of the left internal carotid artery, which crossed the mid-line to terminate in the region of the foramen of Monro (Fig. 1). The calcification observed on the plain $\mathrm{X}$-rays proved to be in the proximal segment of the left middle cerebral artery. A right carotid angiogram demonstrated similar, but much less pronounced, elongation of the supraclinoid segment of the right internal arotid artery and both anterior cerebral arteries filled from that side. Lumbar puncture showed clear fluid at 23 centimeters pressure.

The patient deteriorated soon after the lumbar puncture and developed bilateral fixed pupils. A right coronal burr hole was placed and a catheter inserted into the right lateral ventricle. Air ventriculography showed an encysted right lateral ventricle with displacement of the septum pellucidum across the mid-line (Fig. 2). The ventricular catheter drained, and the patient rapidly improved and was speaking and obeying commands 12 hours later. He was returned to the operating room and further air and positive contrast material instilled into the right lateral ventricle. This showed considerable decompression of the right lateral ventricle, reduction in the mid-line shift, and the passage of air across to the left lateral ventricle. The positive contrast material ran rapidly through to the cervical subarachnoid space (Fig. 3). A ventricular cisternal shunt was then placed in the right lateral ventricle, using a gall bladder $T$ tube. Follow-up pneumoencephalography and angiography five months later showed no change in the angiographic appearance of the ectatic blood vessels. The pneumoencephalogram showed generalized mild hydrocephalus. Brain scan was negative.

Follow-up enquiry three and a half years later found the patient in a chronic care nursing home. He remained mildly demented. The verbal I.Q. was 114 and was interpreted as demonstrating good residual left hemisphere function. The clinical impression was that this score was optimistic. The patient was able to walk, but had a mild left hemiparesis with some accompanying involuntary movements of the left foot.

\section{COMMENT}

The initial clinical picture was one of progressive hydrocephalus with localizing signs referrable to the right hemisphere. Lumbar puncture accelerated the clinical deterioration. After decompression of the right lateral ventricle had restored 


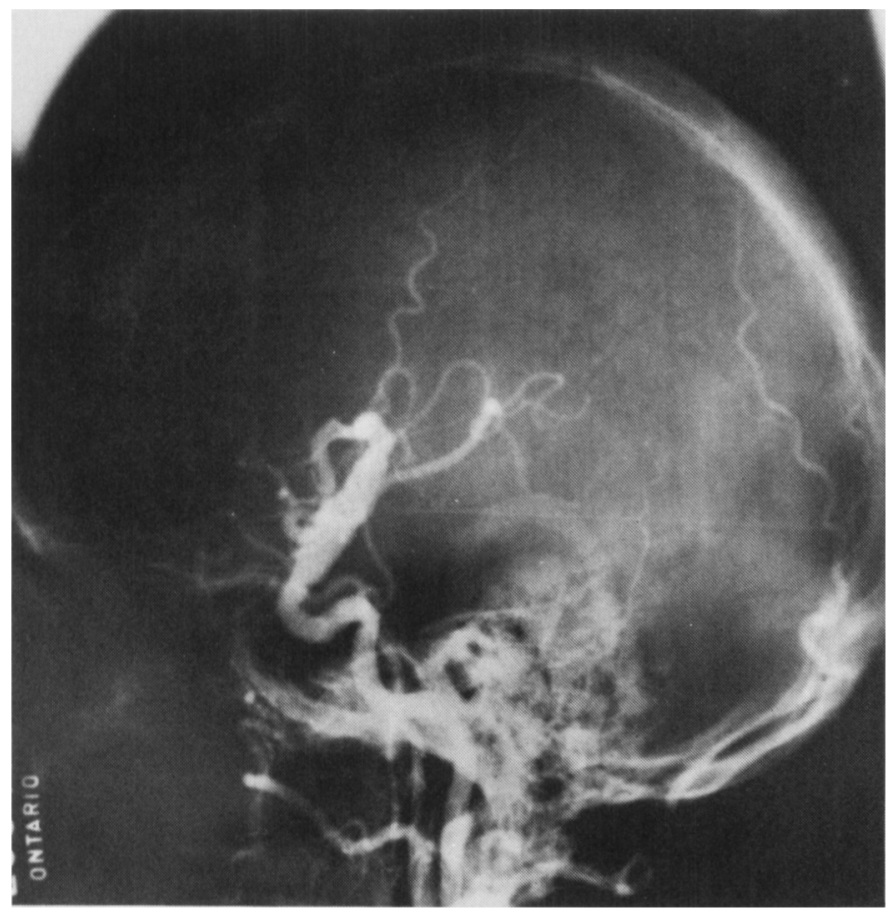

Figure $1-($ A and B) Left carotid angiogram shows marked elongation and some dilatation of the supraclinoid segment of the left internal carotid artery. A right carotid angiogram

Figure 2-Ventriculogram. Note tubular left middle cerebral artery calcification at the foramen of Monro indicated by arrow-heads. Right lateral ventricle is totally obstructed.

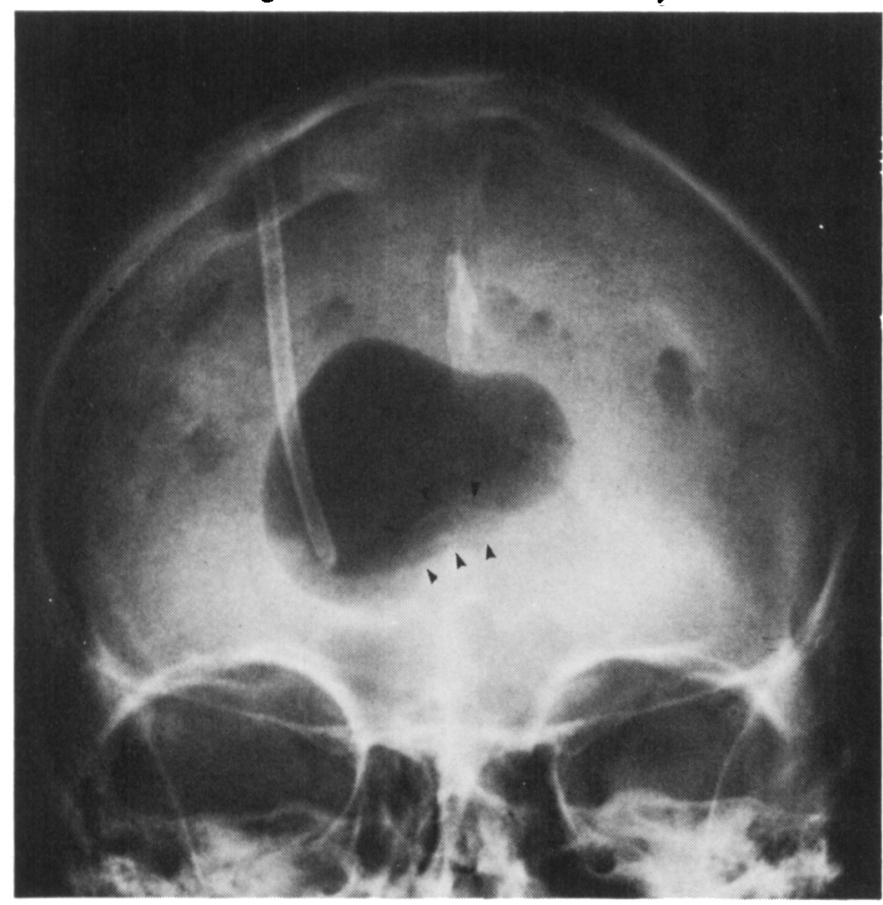

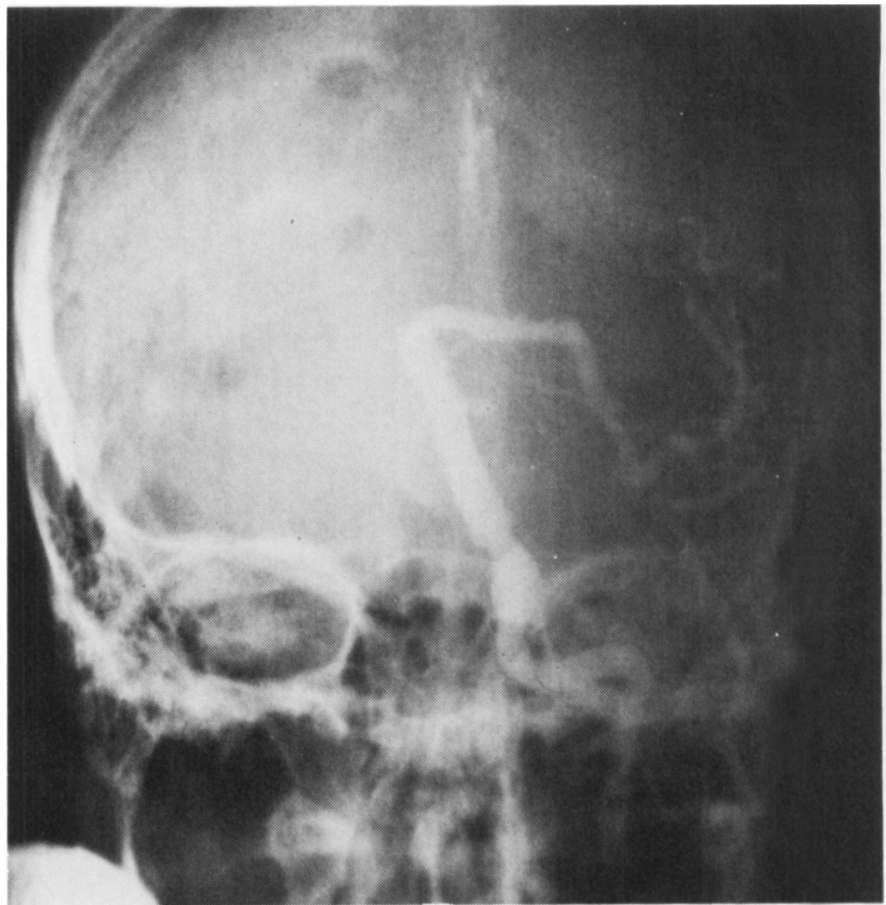

demonstrated both anterior cerebral arteries arising from the right.
Figure 3-Repeat ventriculogram (12 hours later). Air now crosses to the left lateral ventricle. Positive contrast material flows to the fourth ventricle with ease.

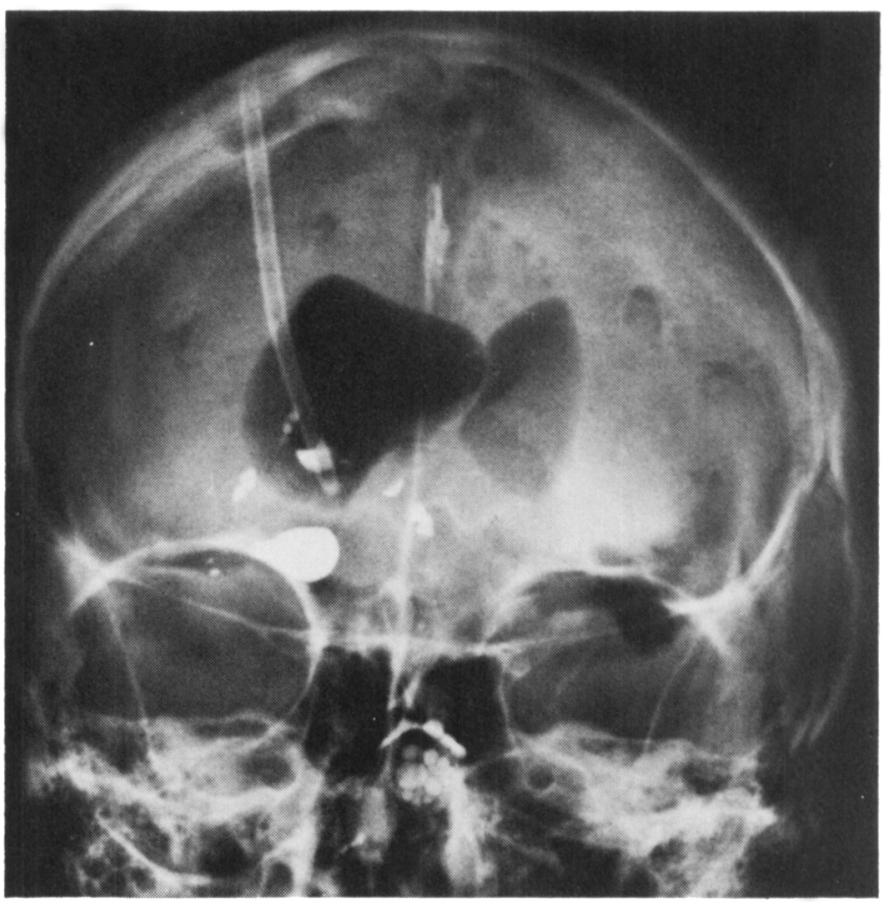


communication between the two lateral ventricles, the right ventricle alone was permanently catheterized. Follow-up studies showed the shunt was working well.

Published reports dealing with ectasia of the major intracranial arteries refer only to the basilar artery, and a certain degree of elongation of this vessel is by no means a rarity. Occasionally this elongation can produce indentation and deformity of the third ventricle. In such cases fairly marked enlargement of the lateral ventricles can result, even though there is no evidence of mechanical ventricular obstruction, and ventricular filling occurs readily following the injection of air by the lumbar route (Breig et al, 1967; Ekbom et al, 1969; Greitz et al, 1969). In all of the reported cases, clinical and pneumographic signs compatible with normal pressure hydrocephalus were present. The hydrocephalus was of the communicating type and there was absence of air over the cerebral hemisphere surfaces (Breig et al, 1967; Ekbom et al, 1969; Greitz et al, 1969). In such cases improvement in the clinical state may follow a ventricular shunting procedure. The pathogenesis of ventricular enlargement in these cases is believed to be due to transmission of pulsations from the ectatic basilar artery across the third ventricle to the foramen of Monro, resulting in a functional obstruction to the outflow of cerebrospinal fluid from the lateral ventricles (Breig et al, 1967; Ekbom et al, 1969).

The case presented here does not fall into the above category. Obstruction of a single lateral ventricle occurred as a direct result of mechanical impingement by a grossly ectatic internal carotid artery, and it should, therefore, be included as another cause, apparently rare, of mechanical ventricular obstruction.

\section{REFERENCES}

BREIG, A., EKBOM, K., KUGELBERG, E. (1967). Hydrocephalus Due to Elongated Basilar Artery. A New Clinicoradiological Syndrome. Lancet 1: 874-875.

EKBOM, K., GREITZ, T., KUGELBERG, E. (1969). Hydrocephalus Due to Ectasia of the Basilar Artery. Journal of Neurological Sciences: 8, 465-477.

EKBOM, K., et al (1969). Cerebrospinal Fluid Pulsations in Occult Hydrocephalus Due to Ectasia of the Basilar Artery. Acta Neuro Chirurgica: 20, 1-8.

GREITZ, T., EKBOM, K., KUGELBERG, E., BREIG, A. (1969), Occult Hydrocephalus Due to Ectasia of the Basilar Artery. Acta Radiologica: 9, 310-316. 